\title{
Sex-dependent differential transcript expression in the placenta of growth restricted infants
}

Jessica O'Callaghan ${ }^{1}$, Vicki Clifton ${ }^{2}$, Peter Prentis ${ }^{1}$, Adam Ewing ${ }^{2}$, Zarqa Saif ${ }^{2}$, and Elise Pelzer $^{1}$

${ }^{1}$ Queensland University of Technology

${ }^{2}$ Mater Research, Translational Research Institute and The University of Queensland

July 13, 2021

\begin{abstract}
Objective: To characterise placental gene expression at term to evaluate sex-specific genetic changes that occur in small for gestational age (SGA) infants. Design: Case control study. Setting: Australian hospitals. Samples: Twelve human placental samples from pregnancies that were either SGA or appropriate for gestational age (AGA). Methods: RNA-sequencing of term placental tissue from both SGA and AGA infants. Candidate genes associated with fetal size and fetal sex were identified using differential gene expression and weighted gene co-expression network analyses. Single-cell sequencing data was used for candidate validation and to estimate candidate transcript expression in specific placental cell populations. Main outcome measures: Functions of differentially expressed genes in the placenta of SGA infants that differed by fetal sex. Results: Differential gene expression and weighted gene co-expression network analyses identified 403 candidate transcripts associated with SGA infants. One hundred and three of these transcripts showed sex-specific expression. Sex-independent transcript expression for genes involved in protein synthesis, and sex-dependent transcript expression for genes involved in cell cycle processes in males and endoplasmic reticulum stress in females was validated (17 and 7 transcripts for females and males) in published placental RNA-sequencing datasets. Conclusions: Sexual dimorphism is an important consideration when examining placental dysfunction and poor fetal growth. This study identified activation of shared and divergent molecular mechanisms (i.e., cell cycle and endoplasmic reticulum stress), in response to an adverse environmental stressor.
\end{abstract}

\section{Hosted file}

OCallaghan_etal_BJOG_08072021.docx available at https://authorea.com/users/425462/articles/ 530295-sex-dependent-differential-transcript-expression-in-the-placenta-of-growthrestricted-infants

\section{Hosted file}

OCallaghan_etal_BJOG_TablesandFigures_06072021.docx available at https://authorea.com/users/ 425462/articles/530295-sex-dependent-differential-transcript-expression-in-the-placentaof-growth-restricted-infants 


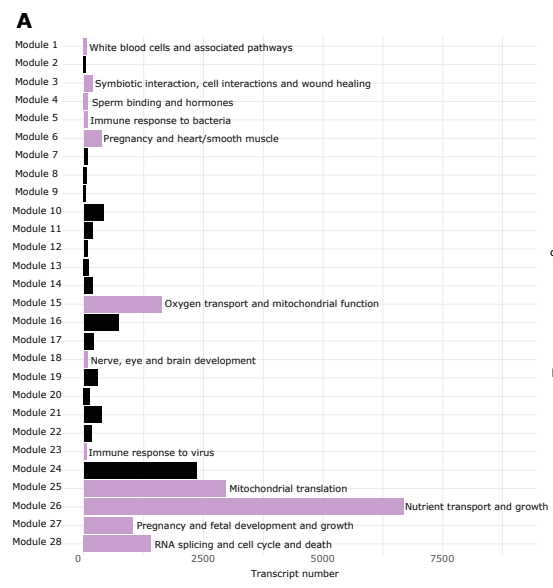

B
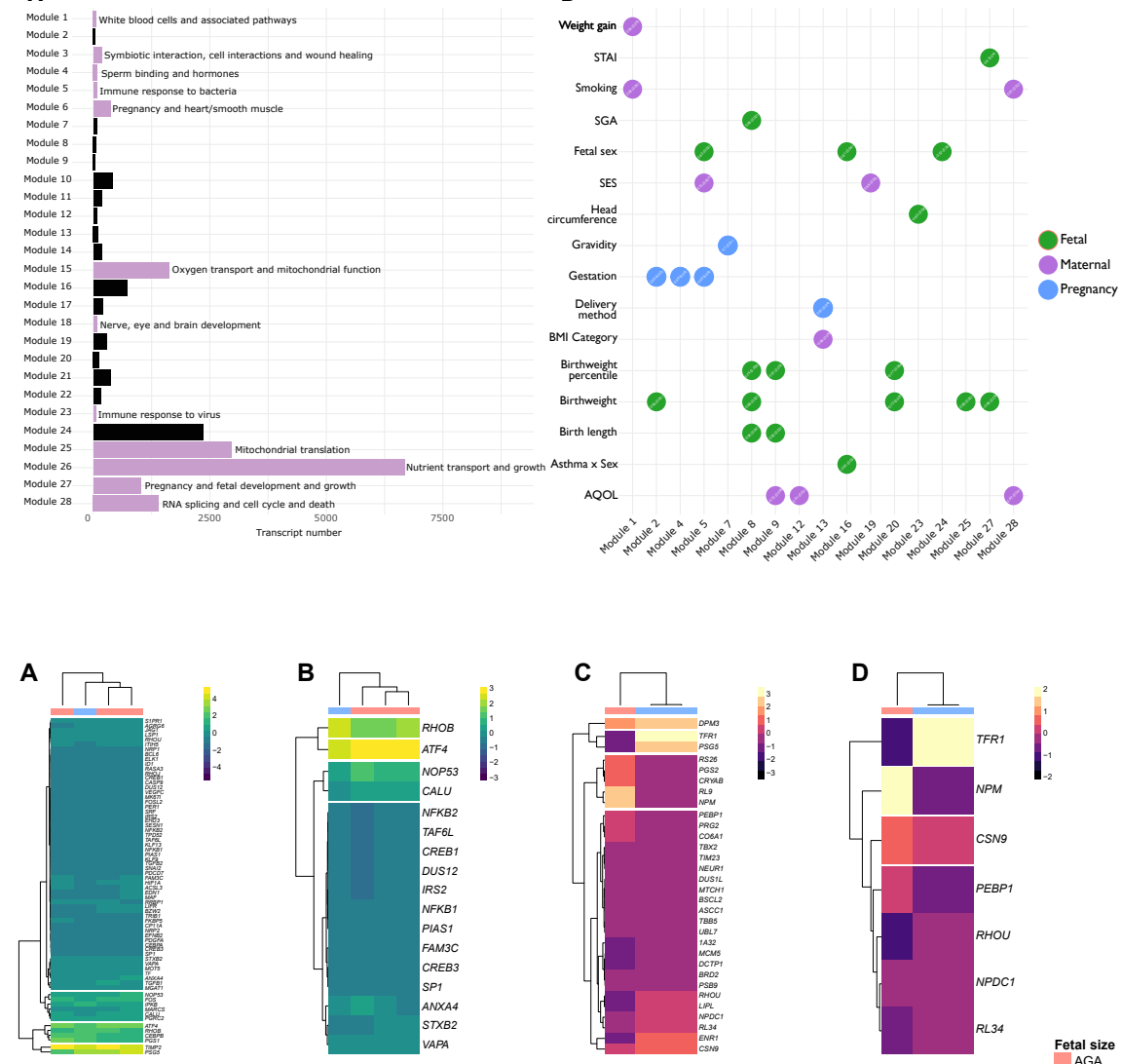


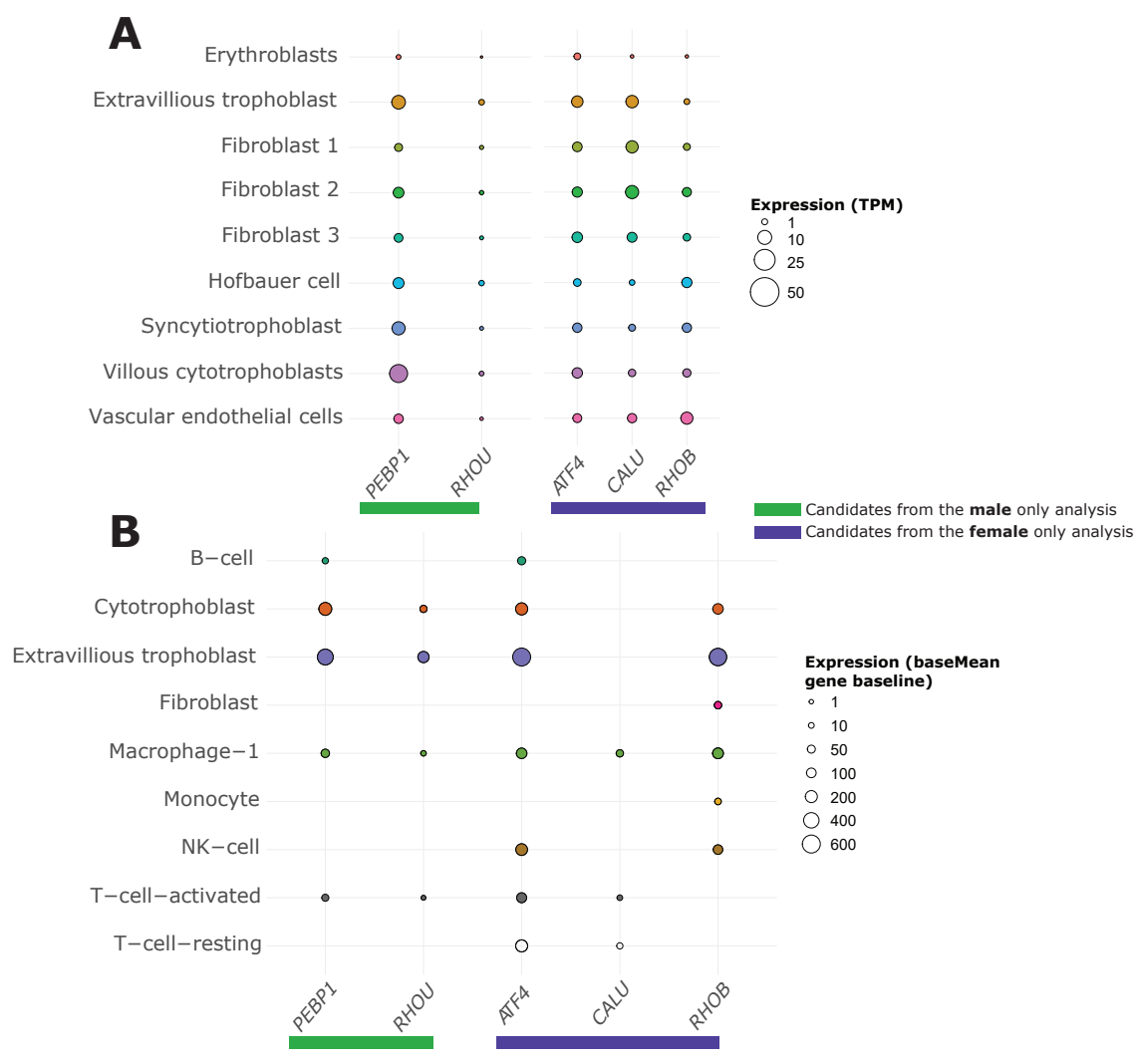

\section{Hosted file}

Supp_Figure_1_01072021.pdf available at https://authorea.com/users/425462/articles/530295sex-dependent-differential-transcript-expression-in-the-placenta-of-growth-restrictedinfants 